\title{
Nifedipine in the treatment of myotonia in myotonic dystrophy
}

\author{
R GRANT,* D L SUTTON, $\uparrow$ P O BEHAN,* J P BALLANTYNE* \\ From the Department of Neurology*, Institute of Neurological Sciences, Southern General Hospital, and the \\ Department of Clinical Physics and Bioengineering, $\dagger$ Glasgow, UK
}

SUMMARY Abnormal calcium transport may be implicated in the membrane defect in myotonic dystrophy. A single blind crossover trial of placebo (t.i.d.), nifedipine $10 \mathrm{mg}$ (t.i.d.) and nifedipine $20 \mathrm{mg}$ (t.i.d.), was performed in 10 patients with myotonic dystrophy. The severity of myotonia was assessed by measuring finger extension time after maximum voluntary finger flexion. A significant improvement in myotonia, after nifedipine, was recorded by this technique and supported by a subjective improvement in $50 \%$ of patients and clinical improvement of greater than $20 \%$ in five patients. Initial grip strength and muscle fatiguability measured by grip strength ergometry were not significantly altered.

Myotonic dystrophy is an autosomal dominant disorder characterised by myotonia and a predominantly distal distribution of muscular wasting. Mytonia, manifest by slow relaxation of muscle after contraction, is clinically most obvious in relaxation of the grasp, and tends to improve with exercise. Abnormalities of the cardiac conduction system, eyes, testes and central nervous system are found in some patients. ${ }^{1}$

There is no satisfactory animal model for myotonic dystrophy. In patients with this disorder, chloride conductance of muscle membrane is not significantly altered but resting muscle membrane potential is reduced. $^{23}$ Abnormalities of erythrocyte and lymphocyte membrane are also described suggesting a widespread cell membrane defect. ${ }^{45}$

Treatment of myotonia has been directed at "stabilising" the muscle membrane. In 1939, Harvey recorded an improvement in myotonia in patients treated with quinine. ${ }^{6}$ Since then procainamide, ${ }^{7}$ corticosteroids $^{8}$ and phenytoin, 9 have also been found to be beneficial in some cases. A small trial revealed that $56 \%$ of cases with myotonia improved on phenytoin and a similar percentage on procainamide; however, phenytoin produced fewer side effects. ${ }^{9}$ More recently tricyclic antidepressants, ${ }^{10}$ lithium $^{11}$ and verapamil ${ }^{12}$ have been successful in improving myotonia refractory to more established

\footnotetext{
Address for reprint requests: Dr R Grant, Magnetic Resonance Imaging Unit, Southern General Hospital, 1345 Govan Rd, Glasgow G51 4TF, UK.

Received 3 April 1986 and in revised form 8 July 1986.

Accepted 10 July 1986
}

treatment. In an uncontrolled trial, the calcium channel blocker, verapamil lessened myotonia in five cases resistant to phenytoin. Verapamil may worsen cardiac conduction abnormalities and is not recommended in patients with myotonic dystrophy of whom $40 \%$ have first degree heart block, over $30 \%$ have interventricular conduction defects, ${ }^{13}$ both of which may progress to complete heart block. ${ }^{14}$

The calcium channel blocker, nifedipine, does not affect cardiac conduction in man, and side effects are minor and relatively infrequent. ${ }^{15} \mathrm{~A}$ single blind crossover trial of placebo, nifedipine $10 \mathrm{mg}$ and nifedipine $20 \mathrm{mg}$ was performed in patients with myotonic dystrophy to assess the effect on the myotonia, muscle power and muscle fatigue.

\section{Methods}

Finger Extension Dynamometer This consisted of a simple goniometer with battery powered potentiometer, which was mechanically coupled, via a miniature universal joint to a lightweight copper tube $150 \mathrm{~mm}$ long. A Velcro strap to fix the finger was connected to the end of the copper tube via another miniature universal joint. The finger/tube arrangement therefore had freedom of movement in any plane. The potentiometer shaft was only rotated by finger extension and flexion but not by lateral movements. The displacement trace of relaxation and contraction was measured by connecting the potentiometer output to a modified chart recorder. The mechanical rotation of the potentiometer was limited to $290^{\circ} \pm 10^{\circ}$ (effective rotation $265^{\circ} \pm 15^{\circ}$ ).

Grip Strength Ergometer Grip strength was recorded by a strain gauge ergometer. This comprised of a handgrip, bonded strain gauge, a strain gauge amplifier and a single 
chart recorder. The strain gauge was bonded on a $3 \mathrm{~mm}$ thick steel bar measuring $110 \mathrm{~m} \times 15 \mathrm{~mm}$. The bar was mounted on a handgrip such that hand pressure on the grip caused distortion of the steel bar and the strain gauge. Calibration of the grip strength dynamometer demonstrated that $4 \cdot 2 \mathrm{Kg}$ of force at the midpoint of the steel bar produced $1 \mathrm{~cm}$ deflection on the chart recorder. There was a linear relationship between force and chart deflection in $\mathrm{cm}$., over the range used. The maximum distortion was adjustable by a screw/nut combination. The foil strain gauge (Showa) had a resting resistance of $119.7 \mathrm{ohm}$, which formed a variable arm of a conventional bridge circuit powered from a low voltage source. During muscle contraction therefore an unbalanced voltage, obtained across the bridge was amplified by a low noise instrumentation amplifier circuit. The power for the amplifier was derived from the main frame of the chart recorder via a DC/DC converter. This voltage powered another circuit consisting of an oscillator driving a piezo-electric sounder to give a $1 \mathrm{~Hz}$ metronome. The metronome prompted the subject to give regular maximum voluntary contractions of the handgrip each second.

Chart recorder The chart recorder used was a single channel ink jet ECG recorder (Mingo 14) modified to bypass its input stages (that is, ECG amplifier). The output from the strain gauge amplifier was AC coupled to the driver stage of the ink jet galvonometer. The time constant was very high, approximately 100 seconds, to produce a DC response.

Technique Before each procedure the chart recorder was calibrated and the test demonstrated to the subject by the examiner. After resting for 10-15 minutes at a room temperature of $22^{\circ} \mathrm{C} \pm 1^{\circ} \mathrm{C}$ subjects were comfortably seated at a table and speed of finger flexion and extension was tested first using the finger extension dynamometer (fig 1). The subject's hand was placed in a supine position and the Velcro finger strap, with recorder arm attached, was tightly placed around the distal phalanx of the index finger. A second Velcro strap was placed across the palmar aspect of the hand and forearm lightly restrained against the table to prevent forearm pronation and wrist extension. It was emphasised that the important movements were speed of finger flexion and extension when requested and that the forearm should not be pronated. The patient was asked to flex his fingers fully for 2 seconds and then to extend the fingers as quickly as possible. After full extension for 2 seconds, a similar command was repeated. Ten such cycles were recorded and chart recorder speed maintained at $10 \mathrm{~mm} / \mathrm{s}$. Both hands were tested. This active finger extension has been referred to by other authors as "Finger relaxation".91617 Finger extension time ("Relaxation Time") after maximum voluntary contraction was measured. This method provides a low resistance method which produces an accurate recording of clinical myotonia.

Grip strength was then assessed, using the ergometer, by asking the subject to squeeze the moulded handgrip as tightly as possible every second (fig 2 ). The piezo-electric metronome prompted the subject at second intervals and the handgrip was fully released between auditory cues. Each hand was tested for 60 maximal contractions and encouragement given after each 10 second period.

In individual patients, recordings of myotonia and grip strength were measured at the same time of day and at the same time after drug administration.

Subjects Control values were obtained from 20 age and sex
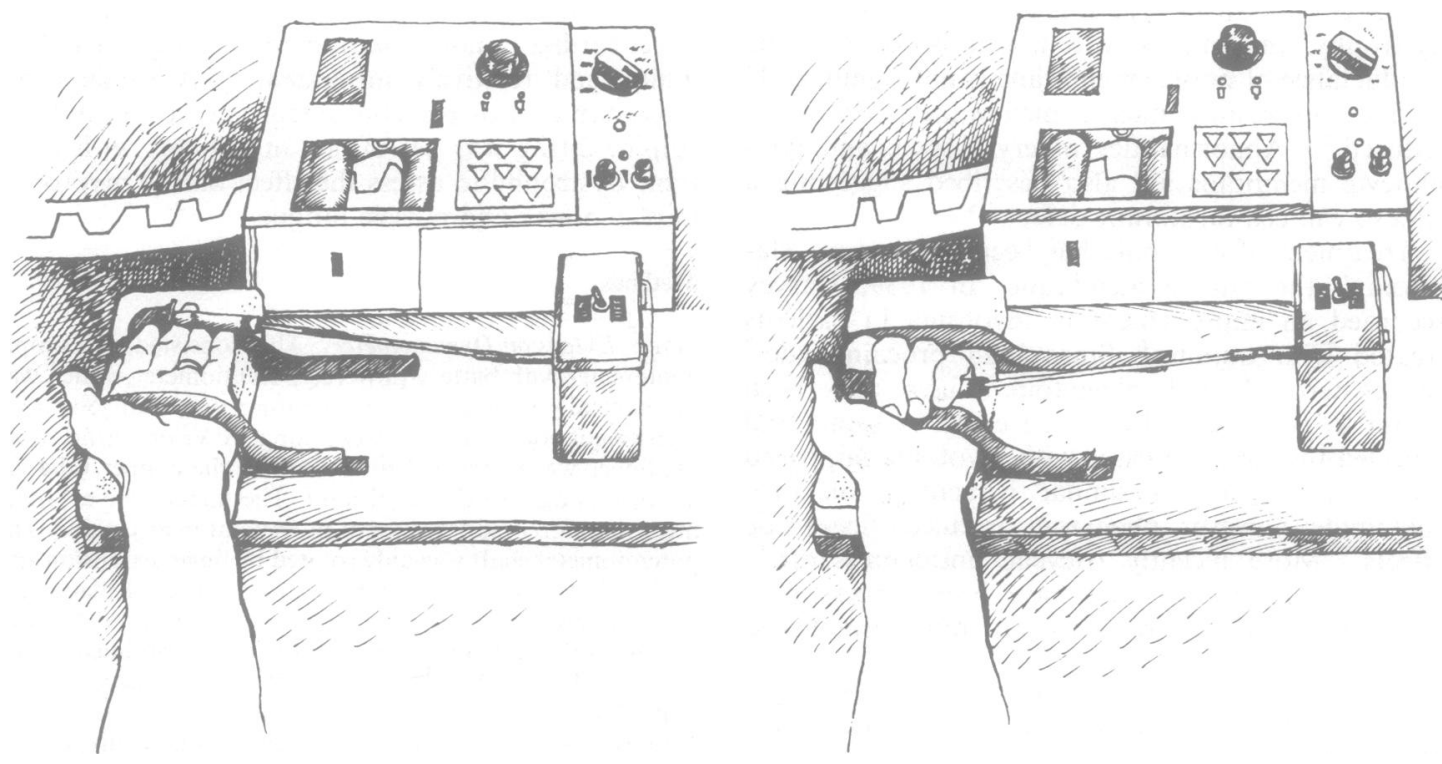

Fig 1 Finger extension dynamometer. 
matched normal volunteers ( 10 males, 10 females) without clinical evidence of neurological or joint disease. Finger extension time, initial grip strength and muscle fatigue after exercise were measured. Ages ranged from 18-65 years. The mean age for males was 40.6 years and 35.2 years for females.

Ten patients (six male, four female) with myotonic dystrophy were studied, aged from 28 to 64 years, mean 40.4 years. Diagnosis was established by accepted clinical criteria $^{2}$ and by electromyographic characteristics. ${ }^{18}$ The range of severity of clinical myotonia and dystrophy varied but, in the past, all had taken phenytoin for myotonia without symptomatic relief. Prior to inclusion in the trial all patients had full clinical neurological examination and electrocardiograph.

Four patients had first degree heart block and two had evidence of an interventricular conduction defect. Finger extension time after maximum voluntary contraction, initial grip strength and muscle fatigue after 1 minute of exercise were measured, in each patient, at the onset of the trial and after each treatment period of either placebo, one tablet three times per day for 2 weeks; nifedipine $10 \mathrm{mg}$ three times per day for 2 weeks or nifedipine $20 \mathrm{mg}$ three times per day for 2 weeks. As a precautionary measure, patients were randomised to either placebo or nifedipine $10 \mathrm{mg}$. As no serious side effects occurred at the lower dosage, the patients were then given nifedipine $20 \mathrm{mg}$. This was a single blind crossover trial during which no drugs were taken. Erect and supine blood pressures and ECGs were recorded after each 2 week period of medication. Drug compliance was assessed by counting the number of tablets returned at the end of each treatment period.

The trial was performed with the informed and written consent of the patients and the approval of the Ethics Committee of the Institute of Neurological Sciences, Glasgow.

\section{Analysis}

Characteristically the myotonia in myotonic dystrophy improves with exercise. However, the initial finger extension after maximum voluntary contraction may not be accompanied by the most prolonged myotonia. In order to overcome this variability the mean value of the first five extension times was measured (m ET) (fig 3). In the majority of patients myotonia was not marked after the fifth repetition. When testing initial grip strength the mean of the first 10 consecutive recordings was taken to represent initial maximal voluntary contraction (m VC i) (fig 4). The mean of the last 10 consecutive maximal voluntary contractions, that is, from 50-60 seconds, was taken to represent the maximum force of voluntary contraction after exercise (m VC e). The degree of muscle fatigue at 1 minute was calculated as:

$$
\frac{\mathrm{mVCi}-\mathrm{mVCe}}{\mathrm{mVCi}} \times 100 \% \text {. }
$$

\section{Statistical Analysis}

Ten patients were studied and myotonia measured in both hands. Analysis of variance was performed to assess whether the variability between each hand was significantly different

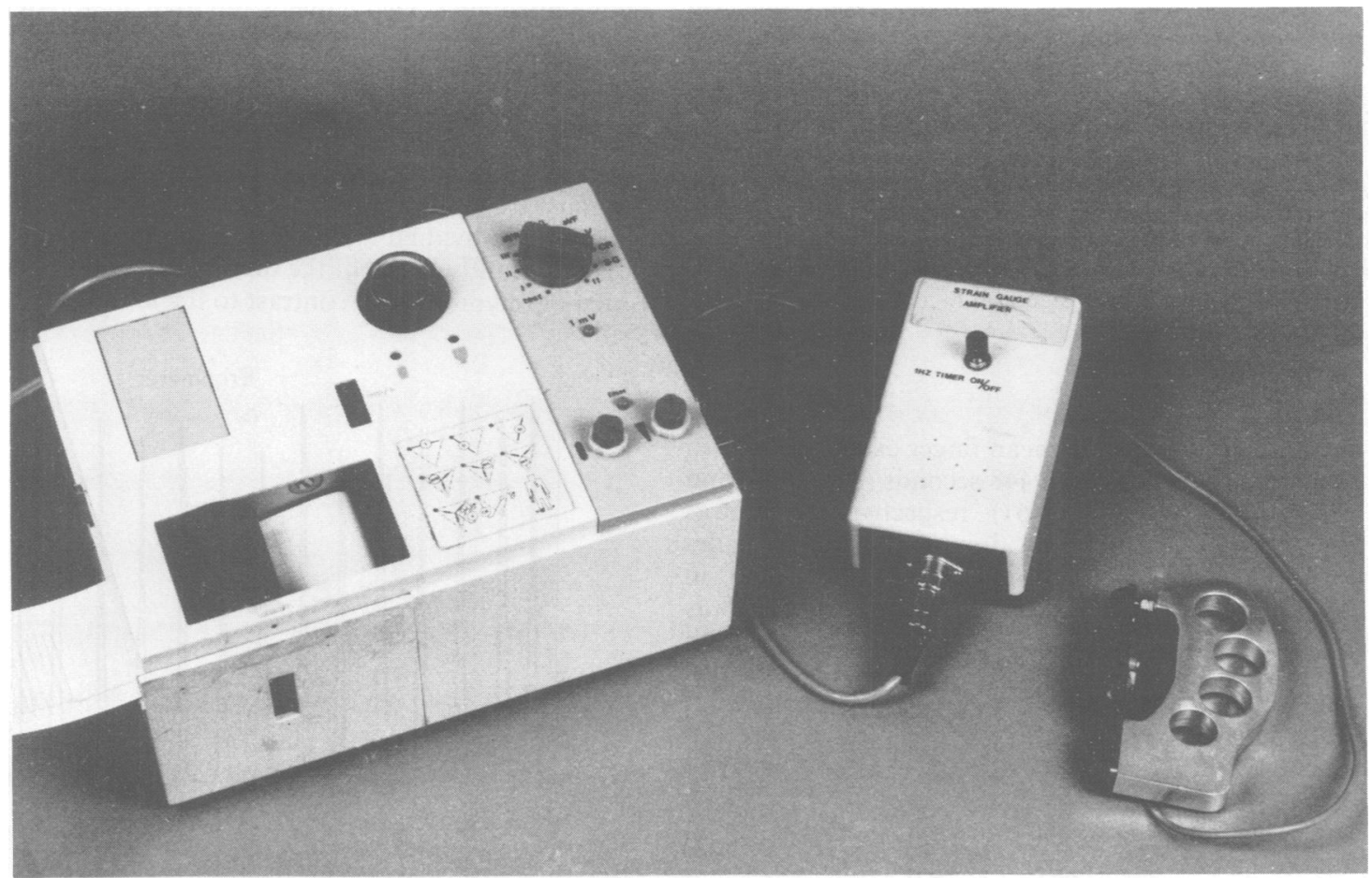

Fig 2 Grip strength ergometer. 
Normal

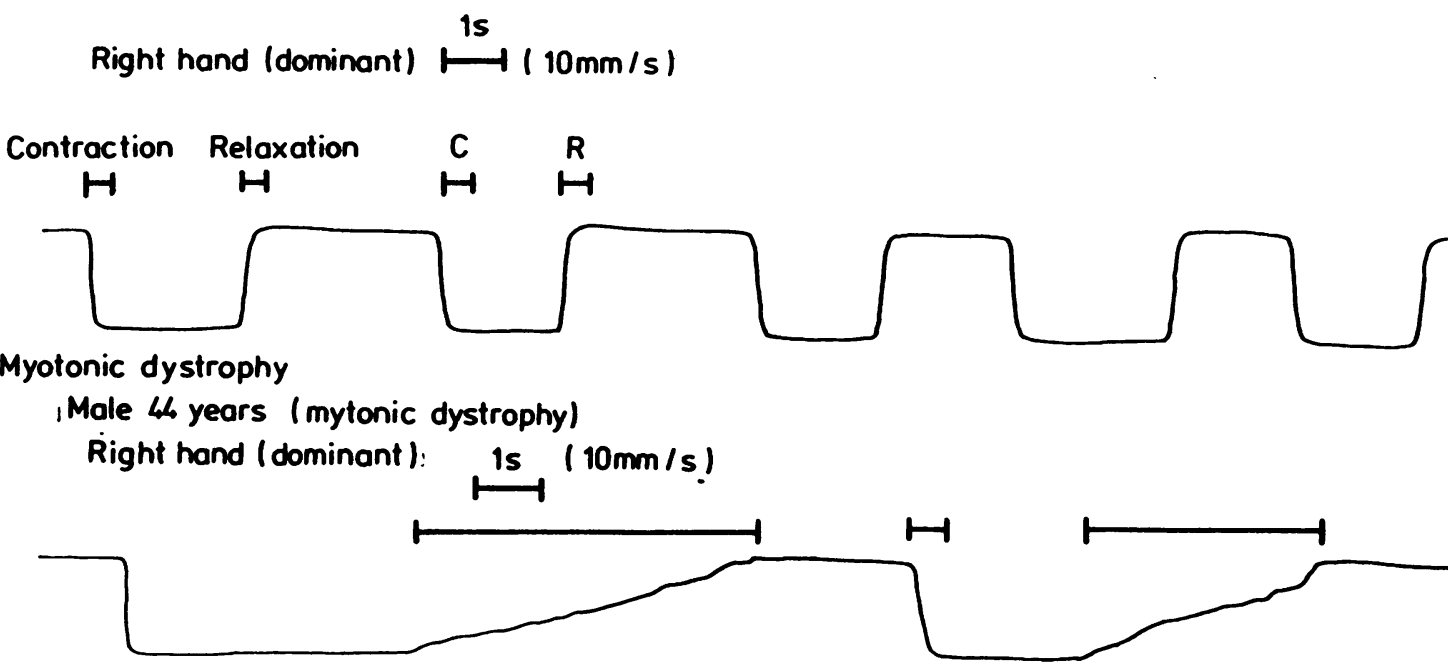

Fig 3 Recording of contraction (flexion) and relaxation (extension) times, measured by dynamometry in a normal subject and a patient with myotonic dystrophy.

from the variability between each patient. This was not significant and therefore the 20 individual results were used for analysis of myotonia.

The Wilcoxon Signed Ranks test for non-parametric data was applied to the 20 results to take account of large improvements in myotonia which might influence the analysis.

When analysing grip strength and muscular fatigue the results from dominant and non-dominant hands were assessed. Response to treatment was again tested by Wilcoxon Signed Ranks analysis on each group of 10 results. $P<0.05$ was considered significant.

\section{Results}

In normal subjects the mean finger extension time in males and females was 0.448 seconds (SD 0.054) and 0.470 seconds (SD 0.061) respectively and was significantly faster in the dominant hand in males ( $p<0.01$, Wilcoxon Signed Ranks test) and in females $(p<0.01)$. The initial grip strength was significantly greater in the dominant hand in both males $(p<0.05)$ and in females $(p<0.01)$. The mean initial grip strength was $24.09 \mathrm{~kg}$ for males and $18.40 \mathrm{~kg}$ for females. Percentage muscle fatigue for normal males was $13 \cdot 12 \%$ and $23.48 \%$ for females (table 1).

Five patients noted a subjective improvement in myotonia on nifedipine $10 \mathrm{mg}$ and five had a significant improvement on nifedipine $20 \mathrm{mg}$. No patient described any worsening of myotonia while taking nifedipine. Two patients reported an apparent deterioration and one an improvement on placebo (table 2). Drug compliance was reasonable with all patients taking at least $88 \%$ of the number of tablets prescribed.

In myotonics, mean finger extension time was significantly prolonged in males and females with wide inter individual differences. Extension time was not significantly faster in the dominant hand in male or female myotonics, in contrast to the findings in the

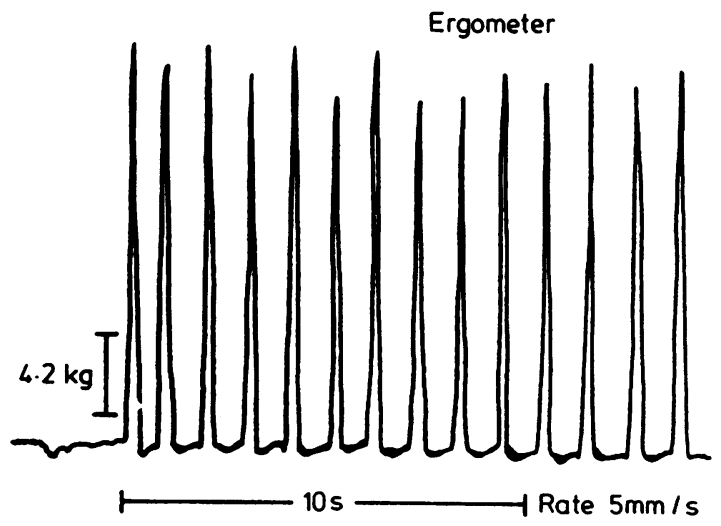

Fig 4 Grip strength ergometric recording in a normal subject. 
Table 1 Extension times grip strength and \% fatigue in normal individuals and patients with myotonic dystrophy

\begin{tabular}{|c|c|c|c|}
\hline & $\begin{array}{l}\text { Mean Extension } \\
\text { Time }(s)\end{array}$ & $\begin{array}{l}\text { Mean Initial } \\
\text { Strength }(\mathbf{k g})\end{array}$ & $\begin{array}{l}\text { Mean percentage } \\
\text { Fatigue }(\%)\end{array}$ \\
\hline Normal subjects $(n=20)$ & $2 \mathrm{SD}$ & $2 S D$ & 2SD \\
\hline $\begin{array}{l}\text { Males dominant } \\
\text { Non-dominant } \\
\text { Females dominant } \\
\text { Non-dominant } \\
\text { Mytonic dystrophy }(n=10)\end{array}$ & $\begin{array}{l}0.436 \pm 0.106 \\
0.461 \pm 0.098 \\
0.465 \pm 0.127 \\
0.476 \pm 0.111\end{array}$ & $\begin{array}{l}24.95 \pm 1 \cdot 01 \\
23.23 \pm 5.01 \\
19.74 \pm 4 \cdot 81 \\
17.05 \pm 4.24\end{array}$ & $\begin{array}{l}10.78 \pm 18.03 \\
15.43 \pm 19.54 \\
23.02 \pm 17.62 \\
23.96 \pm 23.15\end{array}$ \\
\hline $\begin{array}{l}\text { Males } \\
\text { Females }\end{array}$ & $\begin{array}{l}1.800 \pm 2.542 \\
1.497 \pm 1.436\end{array}$ & $\begin{array}{l}10 \cdot 25 \pm 12 \cdot 30 \\
10 \cdot 78 \pm 9 \cdot 01\end{array}$ & $\begin{array}{l}12 \cdot 00 \pm 28 \cdot 15 \\
15 \cdot 00 \pm 12 \cdot 19\end{array}$ \\
\hline
\end{tabular}

control population. Initial grip strength was decreased in patients with myotonic dystrophy, the mean initial grip strength in this sample group being greater in females than in males. This was in keeping with the more marked severity of disease in our male patients. Percentage muscle fatigue was similar in males and females with myotonia.

Results for mean extension time before and after medication are shown in fig 5 . The group mean extension time prior to commencing any medication was $1.76 \mathrm{~s}$, after placebo t.i.d. this was $1.70 \mathrm{~s}$ and after nifedipine $10 \mathrm{mg}$ t.i.d. and nifedipine $20 \mathrm{mg}$ t.i.d. was $1.44 \mathrm{~s}$ and $1.47 \mathrm{~s}$ respectively. Applying the Wilcoxon Signed Ranks test, mean finger extension time was not significantly different between initial and placebo t.i.d. but there was a highly significant improvement in myotonia when initial relaxation time was compared with nifedipine $10 \mathrm{mg}$ t.i.d. $(\mathrm{p}<0.01)$ and nifedipine $20 \mathrm{mg}$ t.i.d. $(\mathrm{p}<0.01)$. Comparing placebo t.i.d. with nifedipine $10 \mathrm{mg}$ t.i.d. the results just fail to reach significance but did reach significance at the $5 \%$ level when compared with nifedipine $20 \mathrm{mg}$ t.i.d. When nifedipine $10 \mathrm{mg}$ t.i.d. was compared with $20 \mathrm{mg}$ t.i.d. there was no significant difference in finger extension time. Seven patients showed a greater than $10 \%$ improvement after nifedipine $10 \mathrm{mg}$ t.i.d. on testing, and six showed a greater than $10 \%$ improvement after nifedipine $20 \mathrm{mg}$ t.i.d. Myotonia in five patients lessened by more than $20 \%$ following nifedipine $10 \mathrm{mg}$ t.i.d. and nifedipine $20 \mathrm{mg}$ t.i.d. when compared with placebo. Those patients who felt subjectively improved, in general, also improved on testing. Of the six patients who showed an improvement in myotonia of greater than $20 \%$ on testing while taking nifedipine, five felt the clinical improvement worthwhile enough to remain on medication. The Wilcoxon Signed Ranks test was applied to compare grip strength prior to medication and grip strength after placebo t.i.d., nifedipine $10 \mathrm{mg}$ t.i.d. and nifedipine $20 \mathrm{mg}$ t.i.d. There was no significant increase or decrease in power after any treatment stage and these drugs had no significant effect on muscle fatigue.

\section{Side Effects}

Nifedipine is well tolerated. Minor side effects such as headache and lethargy are usually associated with vaso-dilation and invariably disappear with continued treatment. Two patients complained of headache and lethargy while on nifedipine $20 \mathrm{mg}$ t.i.d., both of whom developed mild ankle oedema. One patient showed slight $T$ wave flattening on nifedipine $10 \mathrm{mg}$ t.i.d. progressing to $T$ wave inversion in leads 1 and AVL on nifedipine $20 \mathrm{mg}$ t.i.d. All patients had a drop in systolic blood pressure between 5 and $20 \mathrm{mmHg}$ but none developed symptomatic hypotension. Nifedipine should not be used in women of childbearing age wishing to have a family.

Table 2 Subjective responses

\begin{tabular}{llll}
\hline & Placebo & Nifedipine 10 mg tds & Nifedipine 20 mg tds \\
\hline $\begin{array}{l}\text { Myotonia } \\
\text { No change }\end{array}$ & 7 & 5 & 5 \\
$\begin{array}{l}\text { Worse } \\
\text { Improved }\end{array}$ & 2 & 5 & 5 \\
$\begin{array}{l}\text { Strength } \\
\quad \text { No change }\end{array}$ & 1 & & \\
$\quad$ Worse \\
Improved & 7 & 2 & 5 \\
\hline
\end{tabular}




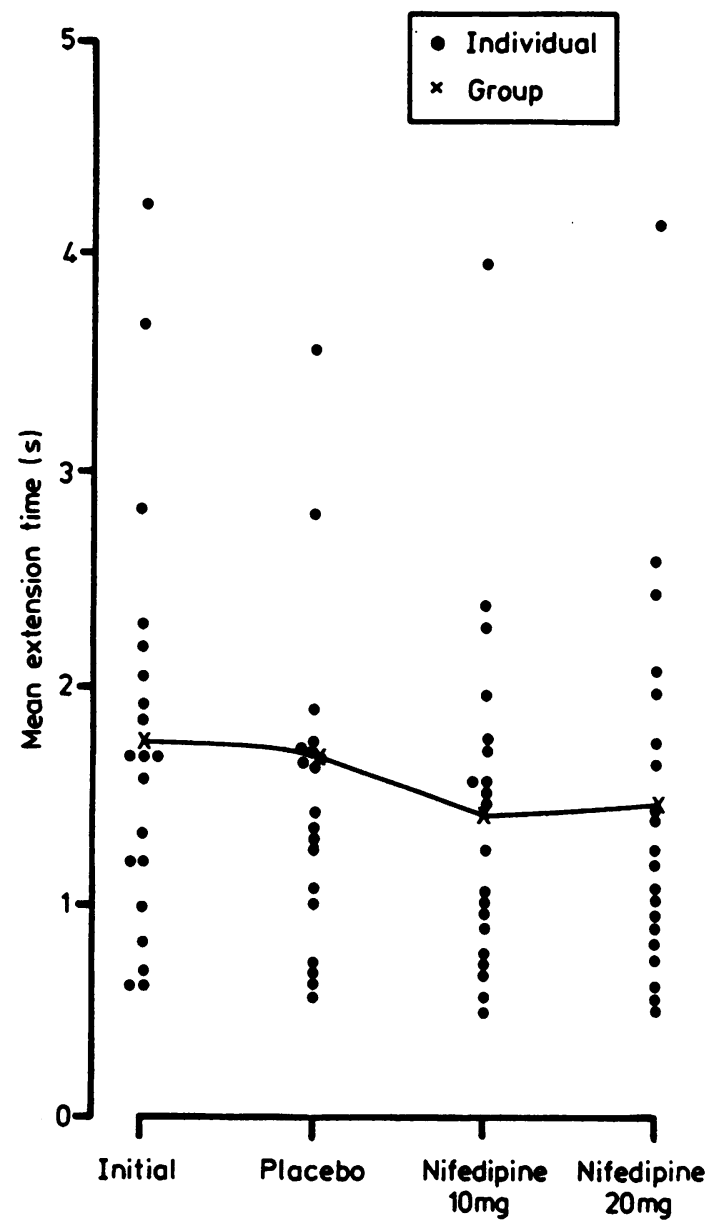

Fig 5 Myotonic dystrophic individual and group mean extension times before and after medication.

\section{Discussion}

It is accepted that the underlying defect in myotonic dystrophy is probably a generalised membrane defect and drugs such as phenytoin which "stabilise" the muscle membrane have been used successfully in treatment of myotonia. Phenytoin is thought to have calcium channel blocking properties ${ }^{1920}$ and it seems possible that this may improve myotonia by blocking calcium transport at a site on the surface membrane or by preventing signal transmission at the tubularsarcoplasmic reticulum junction. As yet it is uncertain whether "charge movement" opens calcium channels in the junctional region or a diffusible chemical transmitter such as calcium acts directly or indirectly to trigger $\mathrm{Ca}^{2+}$ release from the sarcoplasmic reticulum.
The duration of the myotonia may vary depending on previous work load, time of day, temperature and force of initial contraction. The assessment of myotonia is difficult and various methods have been used including timing the relaxation with a stopwatch, ${ }^{17}$ measuring EMG after discharges following maximal voluntary contraction, ${ }^{16}$ intra-arterial potassium infusions to detect changes in myotonia, ${ }^{21}$ and muscle relaxation time after maximum voluntary contraction using an isometric hand dynamometer. ${ }^{22}$

In this study finger extension time from the release of a maximum voluntary flexion contraction to full finger extension was measured as we are more concerned with clinical rather than the electrophysiological assessment of myotonia.

Muscle relaxation rate is determined by metabolic and other factors such as rate of crossbridge cycling and free energy available for calcium reuptake by the sarcoplasmic reticulum. Wiles and Edwards consider that relaxation rate may be an index of the capacity of muscle to liberate energy ${ }^{23}$ and this has been used for measuring rate of energy turnover. ${ }^{24}$ It has been suggested that only part of clinical myotonia is accounted for by the electrical after-discharge, and there may also be a defect in relaxation of crossbridge linkage. ${ }^{25}$ Calcium uptake is influenced by the $\mathrm{Ca}^{2+}$ dependent ATPase which is present in high concentrations in the membrane of the sarcoplasmic reticulum. ${ }^{26}$ Patchy abnormalities in the sarcoplasmic reticulum in myotonic dystrophy are early electron microscopic features and ultrastructural evidence suggests that intracellular tubular changes antedate degeneration of myofibrils. ${ }^{27} \mathrm{High}$ concentrations of $\mathrm{Ca}^{2+}$ have been found in red blood cells and skeletal muscle in myotonic dystrophy. ${ }^{1}$ If there were an abnormality in the calcium dependent ATPase, or in the membrane phospholipids, which are necessary for the optimum activity of the calcium dependent ATPase, free calcium may then accumulate in the muscle cell. Increased intracellular calcium may be toxic to mitochondria by activating membrane bound phospholipases which could cause further breakdown of the muscle membrane or by activating neutral proteases in the myoplasm would cause breakdown of muscle fibres. ${ }^{28}$ The characteristic damage attributed to calcium activated proteases is selective loss of the $Z$ line material on electron microscopy and this is an early finding in myotonic dystrophy and had also been demonstrated after prolonged muscular contraction in normal muscle. ${ }^{29}$ More recently calcium has been found to stimulate prostaglandin production which might activate lysosomal proteases or release free radicals which cause damage by autooxidation. ${ }^{30}$

Since nifedipine blocks calcium channels in the surface membrane of skeletal muscle this may reduce 
intracellular calcium and obviate the above postulated harmful consequences. ${ }^{31} 32$

In this study, $50 \%$ of patients reported a subjective improvement in myotonia after nifedipine and five patients showed a greater than $20 \%$ improvement on testing, supporting the findings of Cook et $a l^{12}$ that calcium channel blockers are of value in myotonia. No obvious effects on grip strength or muscle fatigue were apparent after the short treatment course of 2 weeks. The longterm effects have yet to be studied. Interestingly in animal models, calcium entry blockers have been found to be of some benefit in retarding dystrophic symptoms expressed in chickens and cats. ${ }^{33} 34$ However, a trial of nifedipine in Duchenne muscular dystrophy found it to be safe but to have no significant effect. ${ }^{35}$ Muscle fatigue was not greater in patients with myotonic dystrophy than in normal controls. Whether calcium channel blockers will lead to an arrest of the associated dystrophy is as yet undetermined although the response to these drugs in other forms of muscular dystrophy is not encouraging.

The authors thank Dr Stig Hansen for his help with statistical analysis, Professor TA Simpson for advice and use of the ergometer, Eileen McMeekin and Charles Orr of Medical Illustration Department for photography and art work and Christine FraserCampbell for secretarial help.

\section{References}

1 Baker AB, Baker LH. Clinical Neurology. Vol 3 Muscular Dystrophies, Atrophies and Related diseases. Mytonic Muscular Dystrophy. Harper and Row Philadelphia 1982;37:27-29.

2 Plishker GA, Gitelman HJ, Appel SH. Myotonic muscular dystrophy: altered calcium transport in erythrocytes. Science 1978;200:323-25.

3 McComas AJ, Mrozek K. The elective properties of muscle fibre membranes in dystrophia myotonica and myotonia congenita. J Neurol Neurosurg Psychiatry 1968;31:441-7.

4 Roses AD, Appel SH. Protein kinase activity in erythrocyte ghosts of patients with myotonic muscular dystrophy. Proc Natl Acad Sci USA 1973;70:1855-9.

5 Walker GL, Karagol U, Mathieson EC, Lone RJM, Mastaglia FL. Lymphocyte cupping in myotonic dystrophy. J Neurol Neurosurg Psychiatry 1983;46:90-92.

6 Harvey AM. The mechanism of action of quinine in myotonia and myasthenia. JAMA 1939;112:1562-3.

7 Geschwind N, Simpson JA. Procainamide in the treatment of myotonia. Brain 1955;78:81-91.

8 Garai $\mathrm{O}$. The treatment of dystrophia myotonica with ACTH. J Neurol Neurosurg Psychiatry 1954;17:83-86.

9 Munsat TL. Therapy in Myotonia. A double blind evaluation of diphenylhydantoin, procainamide and placebo. Neurology 1967;17:359-67.
10 Brumback RA, Carlson KM. Treatment of myotonic dystrophy with tricyclics. Muscle Nerve 1983;6:233-4.

11 Gerst JW, Brumback RA, Staton RD. Lithium-induced improvement of myotonia. J Neurol Neurosurg Psychiatry 1984;47:1044-5.

12 Cook JD, Henderson-Tilton AC. Beneficial response to a calcium channel antagonist in myotonic syndromes. Neurology 1984;34 (Suppl 1):193-4.

13 Orndahl G. Thulesius O, Enestrom S, Dehlin O. The heart in myotonic disease. Acta Med Scand 1964;176:479-91.

14 Bork G, Stigell P. Dystrophia myotonica. A follow up study of a family with associated heart disease. Acta Med Scand 1964;175:395-9.

15 Kenny J. Calcium channel blocking agents and the heart. Br Med J 1985;291:1150-2.

16 Lewis I. Trial of diazepam in myotonia-A controlled clinical trial. Neurology 1966;16:831-6.

17 Leyburn P, Walton JN. The treatment of myotonia. A controlled clinical trial. Brain 1959;82:81-89.

18 Simpson JA. Spontaneous activity, myotonia, tetany and cramp. In: Handbook of Electroencephalography and Clinical Neurophysiology. Rémond A, ed. Amsterdam: Elsevier, 1973;16 (B): 74-75.

19 Study RE. Phenytoin inhibition of cyclic guanosine $3^{\prime}: 5^{\prime}-$ monophosphate (c GMP) accumulation in neuroblastoma cells by calcium channel blockade. $J$ Pharmacol Exp Ther 1980;215:575-81.

20 Greenberg DA, Cooper EC, Carpender CL. Phenytoin interacts with calcium channels in brain membranes. Ann Neurol 1984;16:616-7.

21 Durelli L, Mutani R, Piredda S, Fassio F, Delsedime M. The quantification of myotonia: a problem in the evaluation of new antimyotonic drugs. J Neurol Sci 1983;59:167-73.

22 Torres C. Moxley RT, Griggs RC. Quantitative testing of handgrip strength, myotonia and fatigue in myotonic dystrophy. J Neurol Sci 1983;60:157-68.

23 Wiles CM, Edwards RHT. Metabolic heat production in isometric ischaemic contractions of human adductor pollicis. Clin Physiol 1982;2:499-512.

24 Wiles CM, Edwards RHT. The effect of temperature, ischaemia and contractile activity in the relaxation rate of human muscle. Clin Physiol 1982;2:485-97.

25 Wiles CM, Edwards RHT. Weakness in myotonic syndromes. Lancet 1977;2:598-601.

26 Martonosi AN. Mechanisms of $\mathrm{Ca}^{2}$ release from the sarcoplasmic reticulum of skeletal muscle. Physiol Rev 1984;64(4):1240-320.

27 Mussini I, Di Mauro S, Angelini C. Early ultrastructural and biochemical changes in dystrophia myotonica. J Neurol Sci 1970;10:585-604.

28 Wrogemann K, Pena SJG. Mitochondrial overload: a general mechanism for cell necrosis in muscle diseases. Lancet 1976;2:672-4.

29 Jones DA, Jackson MJ, McPhail G, Edwards RHT. Experimental muscle damage: the importance of external calcium. Clin Sci 1984;66:317-22.

30 Edwards RHT, Jackson MJ, Jones DA. Calcium accumulation and lipid peroxidation in muscular dystrophy. J Physiol (Lond) 1984;354:72.

31 Almers W, Fink R, Palade PT. Calcium depletion in frog 
muscle tubules: the decline of calcium current under maintained depolarisation. $J$ Physiol (Lond) 1981;312:177-207.

32 Chiarandini DJ, Stefani E. Calcium action potentials in rat fast twitch and slow muscle fibres. $J$ Physiol (Lond) 1982;335:29-40.

33 Hudecki MS, Pollina CM, Heffner RR. In vivo effects of three calcium blockers on chickens with inherited mus- cular dystrophy. Exp Neurol 1984;84:512-23.

34 Skirboll LR, Howard RA, Dretchen KL. The effect of verapamil on the soleus and gastronemius muscle of the cat in vivo. Eur J Pharmacol 1979;60:15-21.

35 Adams RJ, Rivener MH, Salazar J, Swift TR. Effects of oral calcium antagonists on neuromuscular transmission. Neurology 1984;34 (Suppl 1):132-3. 